\title{
Drug Allergy Profile From a National Drug Allergy Registry
}

\author{
Mona Al-Ahmad ${ }^{1,2 *}$, Jusufovic Edin $^{3}$, Fardous Musa ${ }^{1}$ and Tito Rodriguez-Bouza ${ }^{1}$ \\ ${ }^{1}$ Al Rashed Allergy Centre, Ministry of Health, Kuwait City, Kuwait, ${ }^{2}$ Microbiology Department, Faculty of Medicine, Kuwait \\ University, Kuwait City, Kuwait, ${ }^{3}$ Medical Faculty, University of Tuzla, Tuzla, Bosnia and Herzegovina
}

OPEN ACCESS

Edited by:

Antonino Romano,

Catholic University of the Sacred

Heart, Italy

Reviewed by:

Inmaculada Doña,

Regional University Hospital of

Malaga, Spain

Esther M. Moreno,

University Hospital of Salamanca,

Spain

*Correspondence:

Al-Ahmad Mona

mona.alahmad@ku.edu.kw

Specialty section:

This article was submitted to

Pharmaceutical Medicine and

Outcomes Research,

a section of the journal

Frontiers in Pharmacology

Received: 05 May 2020 Accepted: 09 November 2020

Published: 08 January 2021

Citation:

Al-Ahmad M, Edin J, Musa F and Rodriguez-Bouza T (2021) Drug Allergy

Profile From a National Drug Allergy Registry.

Front. Pharmacol. 11:555666. doi: $10.3389 /$ fphar.2020.555666
Background: Drug hypersensitivity reactions (DHRs) are among the most frequent reasons for consultation in allergy departments and are becoming more common due to increasing prevalence and case complexity.

Objective: To describe the most common drugs associated with clinical reactions, diagnostic methods used, and outcomes of allergic evaluations of a national drug allergy registry over a 12-year period were used.

Methods: An observational, prospective, patient's data registry-based study was conducted to analyze all referrals to the drug allergy outpatient clinics at Al-Rashed Allergy Center, Kuwait, between 2007 and 2019. Demographics, description of DHRs, and results of allergy tests to potential causative medications were reviewed. Diagnostic methods were focused mainly on skin tests (STs) and drug provocation test (DPT), when indicated.

Results: We evaluated 1,553 patients with reported DHRs. The mean age of the population was $41.52 \pm 16.93$ years, and the study population consisted of $63.7 \%$ female patients. Hypersensitivity was finally confirmed in 645 (41.5\%) of patients, probable in 199 (12.8\%), and not confirmed/nonallergic in 709 (45.6\%) patients. Anti-inflammatory drugs and analgesics contributed to $39.22 \%$ of all confirmed drug allergies, followed by antibiotics $38.1 \%$ ( $\beta$-lactam antibiotics (BLs) constituted $73.98 \%$ of all antibiotics and $28.21 \%$ of all drugs), anesthetics $1.8 \%$, and radio-contrast media $0.31 \%$. The majority of reactions were non-immediate $51.44 \%$. The most commonly presenting symptoms among confirmed patients were urticaria $57.80 \%$, angioedema $42.50 \%$, respiratory symptoms $47.60 \%$, and erythema $33.60 \%$. Symptoms of anaphylaxis/anaphylactic shock were reported by 284 patients $(44.00 \%)$ among confirmed cases. The most common method of diagnosis was a positive clinical history (54.4\% in BLs and $90.45 \%$ in nonsteroidal anti-inflammatory drugs (NSAIDs). Among confirmed allergy to BLs, a positive ST was obtained in $31.9 \%$ of patients and positive DPT in $13.7 \%$.

Conclusion: NSAIDs and antibiotics, mainly BLs, are the most commonly implicated in confirmed allergy. In both confirmed and not confirmed/nonallergic cases, BLs are the most frequently involved DHRs which are mainly immediate, and the most commonly presenting symptoms were urticaria, angioedema, and respiratory symptoms. Diagnosis was confirmed mainly by a positive clinical history and when indicated, by positive STs or a DPT.

Keywords: drug allergy, registry, hypersensitivity, allergy, NSAIDs, penicillin 


\section{INTRODUCTION}

A drug hypersensitivity reaction (DHR) can be defined as an adverse drug reaction (ADR), with an immunological etiology, to an otherwise safe and effective therapeutic agent (Park and Demoly, 2012; Böhm and Cascorbi, 2016). Type I hypersensitivity (IgE-mediated) reactions are the most studied among other DHRs that were described by Gell and Coombs (Demoly et al., 2008). DHRs are of significant concern for clinicians and patients as suspected cases may result in avoidance of first-line medications like in cases of suspected $\beta$-lactam antibiotic (BL) allergy that leads to worse outcomes and increased cost (Macy and Contreras, 2014; Su et al., 2017; Sousa-Pinto et al., 2018), and in consequence, both under- and overdiagnosis of DHRs are potential challenges in everyday practice. Although in vivo and in vitro testing including the gold standard drug provocation test (DPT) can confirm the diagnosis, and clinicians have to challenge problems such as the lack of standardized tests to most of the medications, the contraindication for DPT in severe cases, or patient refusal to undergo a DPT with the culprit drug. These problems push clinicians to accept the diagnosis of drug allergy based on clinical history alone on the cases that there is no standardized test or DPT is not as suitable option. Throughout the years, two main groups of drugs have consistently remained prevalent worldwide, BLs and nonsteroidal anti-inflammatory drugs (NSAIDs), with different clinical presentations like cutaneous symptoms of urticaria, angioedema, and respiratory symptoms, among others (Demoly et al., 2014). Many factors affect the DHRs, some are related to the drug itself as the ability to act as a hapten, prohapten, or binding to immune receptors and others to patient factors like female sex, age, history of drug reactions, concomitant infections, or genetics (HLA genotypes) (Gamboa, 2009; Thong and Tan, 2011).

Despite the fact that many studies utilize data from patient's database and electronic medical records, there are not many publications on specifically drug allergy databases, and none of the previously published ones belong to the Middle East region. The reasons might be related to the difficulties and challenges of maintaining and following up patients in a registry-based format. This might be due to the need of a specific database on drug allergy using common standardized procedures (Bousquet et al., 2009). The most remarkable existing database from Europe is the Drug Allergy and Hypersensitivity Database (DAHD) that has provided information regarding cross-reactivity with cephalosporins in confirmed allergic patients to BL (Sidoroff et al., 2010), and of other BLs in proven allergy to cefazolin (Pipet et al., 2011), the need for DPT after negative skin testing (Bousquet et al., 2008), risk of systemic reactions during skin testing (Co Minh et al., 2006), the accuracy of clinical history in patients presenting with reactions to BL (Chiriac et al., 2018), comparison of DHR prevalence in children and adults (Demoly et al., 2012), and NSAIDs patterns of reactions and possible classifications (Caimmi et al., 2012). The objective of this study, based on a national drug allergy registry, was to determine the prevalence, clinical presentation, and drug distribution of DHRs in a country from the Middle East.

\section{METHODS AND MATERIALS}

Al-Rashed Allergy Center is a tertiary public center in Kuwait, and it is a referral center for all drug allergy evaluation in the country, covering both public and private health systems. An initial drug allergy evaluation is performed on all patients referred to our clinic for suspected DHRs, and patients presenting with a suggestive history of DHRs from July 2007 to June 2019 were included in this study. The following data were collected: patient demographics (age and gender), $\operatorname{drug}(\mathrm{s})$ involved in the clinical reaction, signs and symptoms of DHRs (as reported by the patient and/or obtained from their medical records), time of onset of DHRs after drug(s) exposure, results of DPT when indicated, and results of the final evaluation. All patients were evaluated by a detailed clinical history related to ADR or DHR including physical examination (Demoly et al., 1999).

Regarding symptoms, different clinical categories were established; anaphylaxis was defined as per the WHO criteria as a serious allergic reaction that is rapid in onset and might cause death (Simons et al., 2011) and anaphylactic shock, defined as those with anaphylaxis and signs of critical organ hypoperfusion (Thong et al., 2006). Urticaria was defined as hives, angioedema as swelling of the skin, erythema as redness of the skin or mucous membranes, and respiratory symptoms as shortness of breath from upper or lower airways.

Patients were included in the group "multiple" when they refer to the same symptoms upon exposure to three or more different groups of medication. In an attempt to include all groups of drugs that were reported by the patients in our registry, patients were included in the group "others" when they were the only patient in our registry reporting a reaction to a specific group of drugs, and on the contrary, on those cases where more than a single patient refers to symptoms of a specific group of drugs, the group was named by the name of the drug itself (i.e., NSAIDs).

All patients were asked to determine the approximate time elapsed since the intake of the drug and the start of the reaction. Immediate reaction was defined when presenting symptoms, compatible with hypersensitivity reaction, appear till $1 \mathrm{~h}$ after drug administration and nonimmediate reaction was defined when presenting symptoms appear after $1 \mathrm{~h}$.

In our cohort, the cultural background of Middle Eastern patients had a strong influence on the way we based our allergy testing. Our patients are usually less prone to assume DPT risks, and they are favoring a safe testing with alternatives, whenever possible.

Patients were grouped according to the following three categories: 


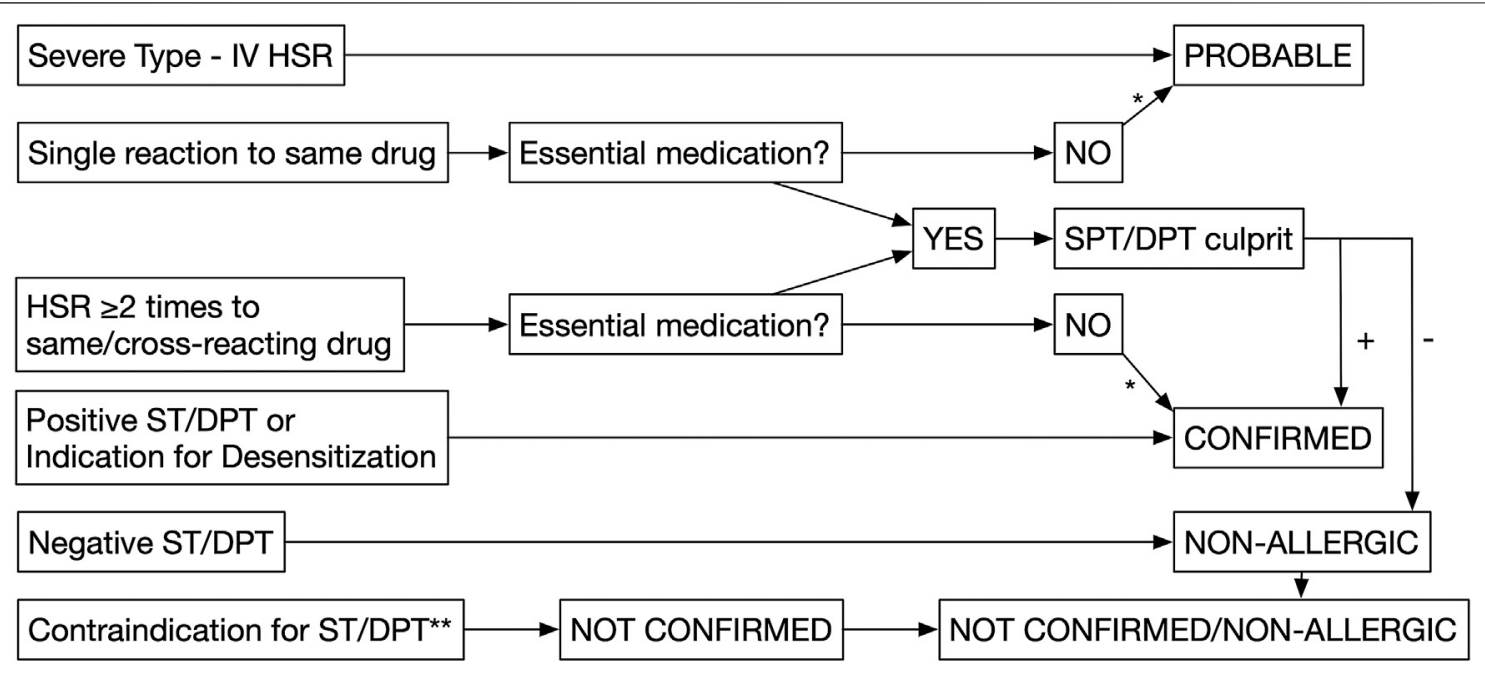

* In case of non-essential medication, ST/DPT with the alternative was performed when needed.

** Patients with comorbidities or not signing consent

FIGURE 1 | Diagnostic methods flowchart.

(1) Confirmed drug allergy: When patients had a positive clinical history alone, defined as symptoms compatible with type I hypersensitivity reactions (immediate), including pruritus, urticaria/angioedema, shortness of breath, on two or more occasions to the same or cross-reacting drugs (graph1), or positive ST/DPT, or if they had an indication for desensitization (Decker et al., 2010).

(2) Probable drug allergy: When patients had a single reaction to the offending drug, or in those presenting with severe cutaneous reactions such as SJS/TEN (Stevens-Johnson syndrome/toxic epidermal necrolysis), AGEP (acute generalized exanthematous pustulosis), and DRESS/DIHS/ HSS (drug reaction with eosinophilia and systemic symptoms/drug-induced hypersensitivity syndrome/ hypersensitivity syndrome).

(3) Not confirmed/nonallergic: Patients are defined as not confirmed when they did not consent for DPT, despite being indicated and in case of contraindication for DPT due to comorbidities or other factors: acute infections; cardiac, hepatic, or renal diseases; pregnancy; breastfeeding; or receiving beta-blockers. Patients are defined as nonallergic when they had negative DPT.

An allergy workup was performed on patients with the following drug categories (Figure 1):

(1) Essential medications: Antibiotic, NSAIDs, monoclonal antibodies, chemotherapy, proton pump inhibitor, corticosteroids, antidiabetic drugs, antihypertensive drugs, anticoagulants, general anesthesia, anticonvulsants, allopurinol, supplemental drugs (iron and vitamin D), and interferon. Skin tests (STs) and
DPT with the culprit drug were used to confirm the diagnosis in these cases. However, when a suitable same efficacy alternative drug is available on those cases with a positive DPT with the culprit drug, additional tests, STs, and DPTs with the suitable alternative were considered in case of cross-reactivity.

(2) Nonessential medications: Other supplemental drugs, hyoscine, antihistamines, and local anesthesia. DPT with the culprit drug was not performed, and instead patients were tested with STs and DPTs to a suitable alternative in case of possible cross-reactivity.

On those patients reporting reactions to radio-contrast media (RCM), the diagnosis was confirmed by STs. If STs were negative, a premedication prior to next infusion was recommended (Pichler, 2010 and American Academy of Allergy; Demoly et al., 2014) and desensitization was performed, if premedication fails (Al-Ahmad and Bouza, 2017).

Patients presenting with erythema alone were tested to the offending medication. A risk assessment was performed by the staff for each individual patient presenting with DHRs, and the decision to proceed with STs/DPTs was decided on an individual basis.

\section{SKIN TESTING}

STs were performed according to the European Network of Drug Allergy (ENDA) (Brockow et al., 2002) guidelines. STs were performed using the dilutions shown in Table 1. The prick test was initially performed, and in those with negative results, was followed by intradermal testing. Intradermal testing is done 
TABLE 1 | Concentrations of the different drugs used for skin prick testing (SPT) and intradermal testing (ID).

\begin{tabular}{|c|c|c|c|}
\hline Drug & SPT & ID & DPT \\
\hline PPL & $0.04 \mathrm{mg} / \mathrm{ml}$ & $0.0004-0.04 \mathrm{mg} / \mathrm{ml}$ & Amoxicillin/clavulanate $875 / 125$ mg \\
\hline MDM & $0.5 \mathrm{mg} / \mathrm{ml}$ & $0.005-0.5 \mathrm{mg} / \mathrm{ml}$ & Same as above \\
\hline Amoxicillin & $20 \mathrm{mg} / \mathrm{ml}$ & $0.2 \mathrm{mg} / \mathrm{ml}$ & Same as above \\
\hline Clavulanic acid & $5 \mathrm{~m}-20 \mathrm{mg} / \mathrm{ml}$ & $0.05-20 \mathrm{mg} / \mathrm{ml}$ & Same as above \\
\hline Ampicillin & $25 \mathrm{mg} / \mathrm{ml}$ & $0.025-25 \mathrm{mg} / \mathrm{ml}$ & Same as above \\
\hline Penicillin G & $10,000 \mathrm{U} / \mathrm{ml}$ & $10-1,000 \mathrm{U} / \mathrm{ml}$ & Same as above \\
\hline Meropenem & $1 \mathrm{mg} / \mathrm{ml}$ & $0.1-1 \mathrm{mg} / \mathrm{ml}$ & $1 \mathrm{gm}$ \\
\hline Cephalosporins & $2 \mathrm{mg} / \mathrm{ml}$ & $0.002,2 \mathrm{mg} / \mathrm{ml}$ & $\begin{array}{l}\text { Ceftriaxone } 2 \text { gm I.V or } \\
\text { Cefuroxime } 500 \text { mg oral }\end{array}$ \\
\hline Hydrocortisone & $2,20 \mathrm{mg} / \mathrm{ml}$ & $0.2,2 \mathrm{mg} / \mathrm{ml}$ & Dexamethasone $5 \mathrm{mg}$ \\
\hline Methylprednisolone & $2,20 \mathrm{mg} / \mathrm{ml}$ & $0.2,2 \mathrm{mg} / \mathrm{ml}$ & \\
\hline lohexol & $350 \mathrm{mg} \mathrm{l} / \mathrm{ml}$ & $35,350 \mathrm{mg} \mathrm{l} / \mathrm{mL}$ & NA \\
\hline lodixanol & 320 mg/ml & $3.2,320 \mathrm{mg} / \mathrm{ml}$ & \\
\hline Lidocaine & $20 \mathrm{mg} / \mathrm{ml}$ & $2 \mathrm{mg} / \mathrm{ml}$ & Lidocaine $2 \mathrm{ml}$ of $20 \mathrm{mg} / \mathrm{ml}$ \\
\hline
\end{tabular}

Abbreviations: PPL, penicilloyl-polylysine; MDM, minor determinant mixture; amoxicillin/clavulanic acid (diater Madrid, Spain), iohexol (GE Health care), ampicillin sodium equivalent to 500 mg ampicillin activity (Bristol-Myers Squibb, United States), Hymox Forte in powder form (Biocheme Spimaco, Saudi Arabia), or amoxicillin commercial kit or clavulanic acid commercial kit (cephalosporin), Penicillin G (Sandoz Gmb H, Kundl-Astria/ Autriche Sanduz), meropenem (AstraZeneca, UK), cefuroxime (Glaxo, Italy), or ceftriaxone (Sandoz, Austria).

by marking the bleb created by the injection of $0.3 \mathrm{ml}$. An immediate positive response was considered when an increase in the diameter of the wheal area was greater than $3 \mathrm{~mm}$ than the saline control and accompanied by erythema that is read 15-20 min after testing (Demoly and Bousquet, 2002). A reading was done after $24-48 \mathrm{~h}$ in the case of nonimmediate reactions. Patch testing was performed in suspicion of type IV reactions.

\section{DPT}

If STs were negative or not available, DPT with the suspected drug was performed (Aberer et al., 2003; Torres et al., 2003). Single-blind placebo-controlled DPT was performed following the ENDA general guidelines (Torres et al., 2003), with slight modifications in some cases. Drugs were administered at increasing doses every 30-90 min until the full therapeutic dose was reached. In patients with reactions induced by NSAIDs, DPT was performed as previously described (Doña et al., 2011). When patient-reported symptoms (e.g., skin and respiratory) or changes in vital signs were observed (heart rate and blood pressure) or a decrease in the peak expiratory flow rate (PEFR), the procedure was stopped, and patients' symptoms were evaluated and treated. If patients tolerated the given drug, they were advised to report any nonimmediate reactions and were considered negative DPT.

We followed the general ENDA recommendations for DPT indications, contraindications, prohibited co-medication, and enhanced safety measures (e.g., intravenous catheter) in case of clinical history of anaphylaxis. Uniformed capsules/preparations, including placebo, delivered in specified doses prepared by the hospital pharmacy or commercially available drugs, were used for DPTs. The oral route was chosen systematically, except for drugs with only intravenous or subcutaneous preparations. All DPTs were performed during one day.

\section{ETHICS COMMITTEE}

All patients were informed about the risk and outcomes of the procedure and provided informed consent. Ethical clearance was granted by Kuwait Research Ethics Committee at the Ministry of Health (Research study number 808/2018).

\section{STATISTICAL ANALYSIS}

Nonparametric and parametric methods are used to calculate statistical significance. The distribution value is determined by D'Agostino and Pearsonomnibus test normality. Student's t-test, Mann-Whitney test, Fisher's test, and $\chi 2$ test were used for calculating the difference between the groups. The ANOVA test was used to calculate the relative difference distribution variance between variables. The statistical hypotheses were tested at a level of $\alpha=0.05$, and the difference between the groups in the sample was considered significant when $p<0.05$ or less. Statistical significance was depicted as $p<0.05, p<0.01$, and $p<$ 0.001. All data were analyzed using GraphPad Prism version 7 (San Diego, California, United States). All the percentages in the tables were calculated from the pooled group of patients, and the difference between pooled groups was calculated using the $\chi^{2}$ test.

\section{RESULTS}

\section{Description of the Total Sample}

We have evaluated 1,553 patients with a history compatible of DHRs, with $65.58 \%$ females with a mean age of $41.52 \pm$ 16.93 years. Among all episodes, $42.18 \%$ were attributed to antibiotics (32.13\% to BLs) and $28.65 \%$ to anti-inflammatory drugs and analgesics (24.66\% to NSAIDs). Drug allergy was confirmed in $645(41.5 \%)$, probable in 199 (12.8\%), and not 
TABLE 2 | Clinical characteristics among patients with confirmed and not confirmed/nonallergic.

\begin{tabular}{|c|c|c|c|c|c|c|c|c|}
\hline \multicolumn{2}{|l|}{ Clinical characteristic } & \multicolumn{2}{|c|}{$\begin{array}{c}\text { Confirmed } \\
(n=645 ; 41.5 \%)\end{array}$} & \multicolumn{2}{|c|}{$\begin{array}{c}\text { Probable } \\
\text { (n = 199; } \\
12.8 \%)\end{array}$} & \multicolumn{2}{|c|}{$\begin{array}{c}\text { Not confirmed/ } \\
\text { nonallergic } \\
(n=709 ; 45.6 \%)\end{array}$} & \multirow[t]{3}{*}{$p$ value } \\
\hline Age (years) & & \multicolumn{2}{|c|}{$42.6 \pm 16.02$} & \multicolumn{2}{|c|}{$40.7 \pm 17.3$} & \multicolumn{2}{|c|}{$43.1 \pm 17.6$} & \\
\hline Females (n; \%) & & 432 & 66.98 & 126 & 63.3 & 463 & 65.03 & \\
\hline \multirow[t]{30}{*}{ Culprit drug } & Allopurinol & 2 & 0.3 & 4 & 2.0 & 2 & 0.3 & $0.0069^{a}$ \\
\hline & Anti-inflammatory and analgesics & 253 & 39.2 & 30 & 15.1 & 162 & 22.8 & $<0.0001^{a}$ \\
\hline & Anesthetic & 12 & 1.9 & 1 & 0.5 & 47 & 6.6 & $<0.0001^{a}$ \\
\hline & Antibiotics & 246 & 38.1 & 72 & 36.2 & 337 & 47.5 & $0.0004^{a}$ \\
\hline & Anticholinergic & 1 & 0.2 & 0 & 0.0 & 1 & 0.1 & 0.8609 \\
\hline & Anticoagulants & 4 & 0.6 & 2 & 1.0 & 4 & 0.6 & 0.7859 \\
\hline & Anticonvulsants & 3 & 0.5 & 7 & 3.5 & 0 & 0.0 & $<0.0001^{a}$ \\
\hline & Antidiabetics & 6 & 0.9 & 0 & 0.0 & 4 & 0.6 & 0.3351 \\
\hline & Antihistamines & 4 & 0.6 & 3 & 1.5 & 5 & 0.7 & 0.4406 \\
\hline & Antihypertensive & 4 & 0.6 & 0 & 0.0 & 2 & 0.3 & 0.3890 \\
\hline & Chemotherapy & 4 & 0.6 & 3 & 1.5 & 2 & 0.3 & 0.1299 \\
\hline & Corticosteroids & 8 & 1.2 & 2 & 1.0 & 14 & 2.0 & 0.4415 \\
\hline & Hormones & 6 & 0.9 & 2 & 1.0 & 2 & 0.3 & 0.2615 \\
\hline & Hyoscine & 4 & 0.6 & 0 & 0.0 & 0 & 0.0 & 0.0594 \\
\hline & Interferon & 1 & 0.2 & 1 & 0.5 & 0 & 0.0 & 0.2112 \\
\hline & Monoclonal antibodies & 7 & 1.1 & 3 & 1.5 & 3 & 0.4 & 0.2209 \\
\hline & Multiple $^{b}$ & 30 & 4.7 & 33 & 16.6 & 38 & 5.4 & $<0.0001^{a}$ \\
\hline & Others ${ }^{c}$ & 32 & 5.0 & 25 & 12.6 & 16 & 2.3 & $<0.0001^{a}$ \\
\hline & Proton pump inhibitors & 8 & 1.2 & 2 & 1.0 & 2 & 0.3 & 0.1221 \\
\hline & Prostaglandin inhibitors & 0 & 0.0 & 2 & 1.0 & 0 & 0.0 & $0.0011^{a}$ \\
\hline & Radio-contrast media & 2 & 0.3 & 1 & 0.5 & 60 & 8.5 & $<0.0001^{a}$ \\
\hline & Supplementals & 8 & 1.2 & 6 & 3.0 & 8 & 1.1 & 0.1221 \\
\hline & $\beta$ lactams ${ }^{\# \#}$ & 182 & 28.2 & 21 & 10.6 & 296 & 41.7 & $<0.0001^{a}$ \\
\hline & Quinolones & 23 & 3.6 & 16 & 8.0 & 19 & 2.7 & $0.0019^{a}$ \\
\hline & Macrolides & 18 & 2.8 & 12 & 6.0 & 15 & 2.1 & $0.0142^{a}$ \\
\hline & Sulphomides & 13 & 2.0 & 7 & 3.5 & 3 & 0.4 & $0.0021^{a}$ \\
\hline & Metronidazole & 3 & 0.5 & 2 & 1.0 & 1 & 0.1 & 0.2027 \\
\hline & NSAIDs & 220 & 34.1 & 22 & 11.1 & 141 & 19.9 & $<0.0001^{\mathrm{a}}$ \\
\hline & Paracetamol & 28 & 4.3 & 7 & 3.5 & 20 & 2.8 & 0.3190 \\
\hline & Opioids & 5 & 0.8 & 1 & 0.5 & 1 & 0.1 & $0.0282^{\mathrm{a}}$ \\
\hline \multirow[t]{5}{*}{ Clinical symptoms } & Urticaria & 373 & 57.8 & 119 & 59.8 & 283 & 39.9 & $<0.0001^{\mathrm{a}}$ \\
\hline & Angioedema & 274 & 42.5 & 132 & 66.3 & 226 & 31.9 & $<0.0001^{a}$ \\
\hline & Erythema & 217 & 33.6 & 173 & 86.9 & 285 & 40.2 & $<0.0001^{a}$ \\
\hline & Respiratory & 307 & 47.6 & 109 & 54.8 & 142 & 20.0 & $<0.0001^{a}$ \\
\hline & Anaphylaxis/anaphylactic shock & 284 & 44.0 & 99 & 49.7 & 77 & 10.9 & $<0.0001^{a}$ \\
\hline \multirow[t]{2}{*}{ Timing } & Immediate & 425 & 65.9 & 25 & 12.6 & 304 & 42.9 & $<0.0001^{a}$ \\
\hline & Nonimmediate & 220 & 34.1 & 174 & 87.4 & 405 & 57.1 & \\
\hline \multirow[t]{2}{*}{ Time elapsed between reaction and study } & $\leq 1$ year & 435 & 67.4 & 162 & 81.4 & 423 & 59.7 & $<0.0001^{a}$ \\
\hline & $>1$ year & 210 & 32.6 & 37 & 18.6 & 286 & 40.3 & \\
\hline
\end{tabular}

${ }^{a}$ Difference was significant statistically.

${ }^{b}$ Multiple: When there was a patient in our registry reporting the same symptoms upon exposure to three or more different groups of medication.

${ }^{c}$ Others: When there was only one patient in our registry reporting a reaction to a specific group of drugs.

confirmed/nonallergic in $709(45.6 \%)$ of patients. Of the total studied patients for each drug, confirmation was obtained in $38.10 \%$ of the patients for antibiotics (28.20\% for BLs) and $39.2 \%$ for anti-inflammatory drugs and analgesics (34.10\% for NSAIDs) (Table 2).

\section{Age and Gender}

Patients with confirmed, probable, and not confirmed/ nonallergic, with immediate and nonimmediate reactions, and with time elapsed between the reaction and study $\leq 1$ and $>1$ year showed a similar age and gender distribution $(p>$ 0.05) (Table 3).

\section{Comparison of Immediate vs. Nonimmediate Reactions}

Patients with confirmed allergy showed more frequently immediate reaction $(65.90 \%)$ than probable drug allergy $(12.6 \%)$ and not confirmed/nonallergic (42.9\%) $p<0.0001$ (Table 2). Timing of reactions was immediate, $\leq 1 \mathrm{~h}$, in $48.55 \%$ of the patients, and nonimmediate, $>1 \mathrm{~h}$, in $51.44 \%$. The ratio of frequency of immediate and nonimmediate reaction was 0.94. In patients with confirmed drug allergy, the frequency ratio of immediate and nonimmediate reactions was 1.93 (Table 4). In patients with confirmed drug allergy, allergy to antibiotics and BLs was more common in patients with 
TABLE 3 | Clinical characteristics among all patients in regard to immediate and nonimmediate drug allergy reactions.

\begin{tabular}{|c|c|c|c|c|c|c|}
\hline \multicolumn{2}{|l|}{ Clinical characteristic } & \multicolumn{2}{|c|}{$\begin{array}{c}\text { Immediate } \\
\text { (n = 754; 48.55\%) }\end{array}$} & \multicolumn{2}{|c|}{$\begin{array}{c}\text { Nonimmediate } \\
\text { (n = 799; 51.45\%) }\end{array}$} & $p$ value \\
\hline Age(years) & & \multicolumn{2}{|c|}{$41.3 \pm 16.4$} & \multicolumn{2}{|c|}{$40.7 \pm 17.4$} & 0.1402 \\
\hline Females (n; \%) & & 497 & 65.9 & 524 & 65.6 & 0.9148 \\
\hline \multirow[t]{4}{*}{ Drug involved } & Antibiotics & 308 & 40.8 & 347 & 43.4 & 0.3045 \\
\hline & Analgesics & 267 & 35.4 & 178 & 22.3 & $<0.0001^{a}$ \\
\hline & $\beta$ lactams & 251 & 33.3 & 248 & 31.0 & 0.3556 \\
\hline & NSAIDs & 225 & 29.8 & 158 & 19.8 & $<0.0001^{a}$ \\
\hline \multirow[t]{5}{*}{ Clinical symptoms } & Urticaria & 388 & 51.5 & 387 & 48.4 & 0.2431 \\
\hline & Angioedema & 304 & 40.3 & 328 & 41.1 & 0.7962 \\
\hline & Erythema & 237 & 31.4 & 438 & 54.8 & $<0.0001^{a}$ \\
\hline & Respiratory & 359 & 47.6 & 199 & 24.9 & $<0.0001^{a}$ \\
\hline & Anaphylaxis/anaphylactic shock & 308 & 40.8 & 152 & 19.0 & $<0.0001^{a}$ \\
\hline \multirow[t]{2}{*}{ Time elapsed between reaction and study } & $\leq 1$ year & 506 & 67.1 & 514 & 64.3 & 0.2616 \\
\hline & $>1$ year & 248 & 32.9 & 285 & 35.7 & \\
\hline
\end{tabular}

${ }^{a}$ Difference was significant statistically.

TABLE 4 | Clinical characteristics among patients with confirmed drug allergy in regard to immediate and nonimmediate drug allergy reactions.

Clinical characteristic

Age (years)
Females (n; \%)
Drug involved

Clinical symptoms

Time elapsed between reaction and study

${ }^{a}$ Difference was significant statistically.

Drug involved

\section{Immediate \\ (n = 425; 65.9\%)}

68.9

\begin{tabular}{lr}
\multicolumn{2}{c}{$42.7 \pm 15.7$} \\
293 & 68.9 \\
171 & 40.2 \\
194 & 45.6 \\
134 & 31.5 \\
167 & 39.3 \\
249 & 58.6 \\
194 & 45.6 \\
126 & 29.6 \\
267 & 62.8 \\
248 & 58.4 \\
286 & 67.3 \\
139 & 32.7
\end{tabular}

\begin{tabular}{ccc}
\multicolumn{2}{c}{$\begin{array}{c}\text { Non-immediate } \\
\text { (n = 220; 34.1\%) }\end{array}$} & $\boldsymbol{p}$ value \\
\multicolumn{2}{c}{$41.1 \pm 16.6$} & 0.8995 \\
139 & 63.2 & 0.1577 \\
59 & 26.8 & $0.0007^{\mathrm{a}}$ \\
75 & 34.1 & $0.0054^{\mathrm{a}}$ \\
48 & 21.8 & $0.0098^{\mathrm{a}}$ \\
53 & 24.1 & $0.0001^{\mathrm{a}}$ \\
124 & 56.4 & 0.6142 \\
80 & 36.4 & $0.0288^{\mathrm{a}}$ \\
91 & 41.4 & $0.0037^{\mathrm{a}}$ \\
40 & 18.2 & $<0.0001^{\mathrm{a}}$ \\
36 & 16.4 & $<0.0001^{\mathrm{a}}$ \\
149 & 67.7 & 0.9296 \\
71 & 32.3 & \\
\hline
\end{tabular}

Antibiotics
Analgesics
$\beta$ lactams
NSAIDs
Urticaria
Angioedema
Erythema
Respiratory
Anaphylaxis/anaphylactic shock
$\leq 1$ year
$>1$ year

Nonimmediate
(n $=799 ; 51.45 \%)$ 
TABLE 6 | Clinical characteristics of patients with confirmed drug allergy in regard to anaphylaxis.

\begin{tabular}{|c|c|c|c|c|c|c|}
\hline \multicolumn{2}{|c|}{ Clinical characteristic } & \multicolumn{2}{|c|}{$\begin{array}{l}\text { With anaphylaxis/ } \\
\text { anaphylactic shock } \\
\text { (n = 284; } 44.03 \%)\end{array}$} & \multicolumn{2}{|c|}{$\begin{array}{l}\text { Without anaphylaxis/ } \\
\text { anaphylactic shock } \\
\text { (n=361; 55.97\%) }\end{array}$} & $p$ value \\
\hline Age (years) & & & & & & 0.6409 \\
\hline Females (n; \%) & & 206 & 72.5 & 226 & 62.6 & $0.0089^{a}$ \\
\hline \multirow[t]{4}{*}{ Drug involved } & Antibiotics & 125 & 44.0 & 121 & 33.5 & $0.0071^{a}$ \\
\hline & Analgesics & 107 & 37.7 & 146 & 40.4 & $<0.0001^{a}$ \\
\hline & $\beta$ lactams & 103 & 36.3 & 79 & 21.9 & 0.3576 \\
\hline & NSAIDs & 91 & 32.0 & 129 & 35.7 & $<0.0001^{a}$ \\
\hline \multirow[t]{4}{*}{ Timing } & Immediate & 248 & 87.3 & 177 & 49.0 & $<0.0001^{a}$ \\
\hline & Nonimmediate & 36 & 12.7 & 184 & 51.0 & \\
\hline & $\leq 1$ year & 198 & 69.7 & 237 & 65.7 & 0.3098 \\
\hline & $>1$ year & 86 & 30.3 & 124 & 34.3 & \\
\hline
\end{tabular}

${ }^{a}$ Difference was significant statistically.

\section{Time Since Reaction to Study}

Patients with confirmed drug allergy showed more frequent time elapsed between the reaction and study $\leq 1$ year than not confirmed/nonallergic patients, but less frequent than patients with probable allergy (Table 2). The time elapsed between reaction and study $>1$ year was similar to the ones without anaphylaxis/anaphylactic shock (Table 6).

\section{Comparison of Confirmed and Not Confirmed Cases}

Patients with confirmed drug allergy showed more frequent $(p<$ 0.05 ) allergy to analgesics, NSAIDs, and opioids than patients with probable drug allergy and not confirmed/nonallergic. However, patients with probable drug allergy showed more frequent allergy to allopurinol, anticonvulsants, multiple drugs, other drugs, prostaglandin inhibitors, quinolones, macrolides, and sulphomides than patients with confirmed and not confirmed/ nonallergic. Furthermore, not confirmed/nonallergic patients showed more frequent allergy to anesthetics, antibiotics, radiocontrast media, and $\beta$ lactams than patients with probable and confirmed drug allergy (Table 2).

All symptoms (urticaria, angioedema, respiratory symptoms, and anaphylaxis) were more common in patients with confirmed and probable drug allergy, rather than in not confirmed/nonallergic patients, with the exception of erythema, which was most common in patients with probable allergy (Table 2). Anaphylaxis was shown in $44.00 \%$ of confirmed patients, which was $18.28 \%$ of the total population (Table 2). In this group of patients, angioedema, erythema, respiratory symptoms, and anaphylaxis were similarly distributed in allergy to antibiotics and analgesics. However, urticaria was more frequent in allergy to antibiotics than in analgesics allergy. Urticaria and anaphylaxis were more common in BL than NSAID hypersensitivity, while angioedema, erythema, respiratory symptoms, and immediate and nonimmediate reactions were similarly distributed between BL and NSAID hypersensitivity (Table 5). In patients with confirmed drug allergy, patients with anaphylaxis were younger than those without anaphylaxis, but these differences were not statistically significative $(p=0.6409)$ (Table 6).
Patients with anaphylaxis/anaphylactic shock showed more common allergy to antibiotics, but less common to analgesics and NSAIDs, than patients without anaphylaxis/anaphylactic shock (Table 6). Among the anaphylactic cases, antibiotics were the culprit in $44 \%$ of cases, whereas anti-inflammatory drugs and analgesics as a group was responsible in $37.7 \%(<0.0001)$ (Table 6).

In regard to diagnosis, the most common method was a positive clinical history (54.4\% in BLs and $90.45 \%$ in nonsteroidal antiinflammatory drugs (NSAIDs)). Among confirmed allergy to BLs, positive ST was obtained in $31.9 \%$ of patients and positive DPT in 13.7\% (Table 7). Among patients with confirmed drug allergy, allergy diagnosis was made more frequently by positive history alone for the following drugs: BLs, quinolones, macrolides, metronidazole, sulphomides, NSAIDs, paracetamol, opioids, and RCM (Table 7).

\section{DISCUSSION}

To our knowledge, this is the first published drug allergy database in the Middle East region. We hypothesize that this might be due

TABLE 7 | Diagnostic methods in confirmed drug allergy.

\begin{tabular}{|c|c|c|c|c|c|c|c|}
\hline \multirow[t]{2}{*}{ Drug } & \multicolumn{2}{|c|}{$\begin{array}{l}\text { Positive by } \\
\text { history only }\end{array}$} & \multicolumn{2}{|c|}{$\begin{array}{l}\text { Positive } \\
\text { by skin } \\
\text { prick test }\end{array}$} & \multicolumn{2}{|c|}{$\begin{array}{c}\text { Positive by } \\
\text { DPT }\end{array}$} & \multirow[t]{2}{*}{$p$ value } \\
\hline & $n$ & $\%$ & $\mathrm{n}$ & $\%$ & $\mathrm{n}$ & $\%$ & \\
\hline$\beta$ lactams $(n=182)$ & 99 & 54.4 & 58 & 31.9 & 25 & 13.7 & $<0.0001^{a}$ \\
\hline Quinolones $(n=23)$ & 20 & 86.9 & 0 & 0.0 & 3 & 13.1 & $<0.0001^{a}$ \\
\hline Macrolides $(n=18)$ & 18 & 100.0 & 0 & 0.0 & 0 & 0.0 & $<0.0001^{a}$ \\
\hline Metronidazole $(n=3)$ & 3 & 100.0 & 0 & 0.0 & 0 & 0.0 & $<0.0001^{a}$ \\
\hline Sulphomides $(n=13)$ & 13 & 100 & 0 & 0.0 & 0 & 0.0 & $<0.0001^{a}$ \\
\hline NSAIDs $(n=220)$ & 199 & 90.45 & 0 & 0.0 & 9 & 9.54 & $<0.0001^{a}$ \\
\hline Paracetamol $(n=28)$ & 25 & 89.29 & 0 & 0.0 & 3 & 10.71 & $<0.0001^{a}$ \\
\hline Opioids ( $n=5$ ) & 5 & 100 & 0 & 0.0 & 0 & 0.0 & $<0.0001^{a}$ \\
\hline $\operatorname{RCM}(n=2)^{b}$ & 0 & 0.0 & 0 & 0.0 & 0 & 0.0 & - \\
\hline
\end{tabular}

${ }^{a}$ Difference was significant statistically.

${ }^{b}$ Desensitization was done for 12 patients who had reaction to NSAIDs.

${ }^{c}$ Desensitization was done for two patients who had reaction to RCM.

$D P T$, drug provocation test. 
not only to the complexity and time-consuming task of developing a standardized database in a registry-based format (Bousquet et al., 2009) but also to other factors as the recently developed electronic databases, the relatively recent increased development of the health systems in Middle East compared with those in Europe and North America. This is a drug allergy registry-based study that was done over 12 -year duration. The diagnosis in our study was confirmed in $41.5 \%$ of cases, and this compares to other European studies where drug allergy was confirmed in $37.4 \%$ and not confirmed/nonallergic in $62.6 \%$ (including $13.4 \%$ with contraindications for testing) (Doña et al., 2012), and American studies, where at least one drug allergy was confirmed in $19.66 \%$ of patients (Blanca et al., 2020). This difference can be attributed to the confirmation criteria that were adapted in our study, which specifically include patients who had a positive clinical history alone. This is a key factor to understand some of the diagnostic differences with other studies.

Our sex and age distribution is similar to other studies that report $64.58-71.9 \%$ of females, with a mean age of $43.7-48.9$ years (Doña et al., 2012; Gabrielli et al., 2018; Blanca et al., 2020). In our cohort, reactions occurred $\leq 1 \mathrm{~h}$ in $48.55 \%$ of all the patients and $\geq 1 \mathrm{~h}$ in $51.44 \%$. Interestingly, these results are similar to those of a study by Bousquet PJ et al. (Bousquet et al., 2008), which excluded type IV reactions and found that reactions occurring $\leq 1 \mathrm{~h}$ after drug intake in $36.6 \%$ of patients. However, other studies (BenShoshan et al., 2018) focused on BL reactions and found a reaction $\leq 1 \mathrm{~h}$ after drug intake in $19.9 \%$ and after $24 \mathrm{~h}$ in $34.4 \%$.

Many studies have evaluated the timing since reaction; interestingly, the average delay was 299.7 months in a large study, which was reduced to 43 months on those confirmed for one drug and 76.9 months for multiple drugs (Blanca et al., 2020). On the other hand, a study with BLs showed an average of 54.7 months for not confirmed/nonallergic and 25.8 months for confirmed patients (Bousquet et al., 2008). These results are consistent with ours, with confirmed and probable patients presenting earlier to our clinic for consultation.

The number of confirmed and probable patients showing a time elapse since reaction $<1$ year was significantly higher than for those not confirmed/nonallergic, and this is consistent with other studies following the decrease in positive ST responses after 1,3 , and 5 years which showed a decrease of $68.1,50$, and $36.1 \%$ for cephalosporins (Demoly et al., 2003) or 80.6, 78.3, and 70.6\% for patients presenting positive STs to benzylpenicilloyl (BPO) or minor determinant mixture $(\mathrm{MDM})$ or 50,54 , and $0 \%$ for patients reacting to amoxicillin side chains (Blanca et al., 1999). This decrease in sensitivity over time has also been reported in NSAIDs for NIUA (NSAID-induced urticaria/ angioedema) and SNIUAA (single NSAID-induced urticaria/ angioedema and anaphylaxis) (Doña et al., 2020).

Of the total studied patients for each drug, confirmation was obtained in $42.17 \%$ of the patients with antibiotics $32.13 \%$ for BLs) and $28.65 \%$ with anti-inflammatory drugs and analgesics (24.66\% for NSAIDs). In other studies, hypersensitivity to NSAIDs was confirmed in $19.6-27 \%$ and BLs in $18.4-6.99 \%$ (Bourke et al., 2015; Cornejo-García et al., 2019; Blanca et al., 2020). Confirmation was reached for BLs in $45.6 \%$ of the patients by means of STs or DPTs, and the remaining by clinical history alone. When compared with American studies of patients allergic to BLs, one study showed that $7.35 \%$ of tested individuals had positive penicillin ST results, with only $1.6 \%$ of the negative ST patients had a reaction to the DPT (Macy et al., 2009). Another study (Blanca et al., 2020) showed that $14.14 \%$ of tested individuals had positive ST or DPT results. In an Australian study that evaluated the effectiveness of penicillin allergy delabeling of 341 patients, a positive ST was found in 42 (12.3\%) of patients, which was similar to our findings, in which 58 of $499 \mathrm{BL}$ patients (11.62\%) had positive STs (Bourke et al., 2015). In comparison to European studies, our results compare with a multicenter study that included patients with reactions to BLs only (Chiriac et al., 2018; Ben-Shoshan et al., 2018), in which $23.6 \%$ of the studied patients were confirmed as allergic by means of STs or DPTs only. Furthermore, the number of confirmed patients in these studies was lower than ours as positive testing was generally required for confirmation. Previous studies from our group showed that our data compare more with European than with American studies (Al-Ahmad et al., 2014; Al-Ahmad and Rodriguez-Bouza, 2018); this multicenter study can provide an idea of additional patient's number required to be positive using our criteria of positive BL allergy based on clinical history alone.

The frequency of drug allergy types varied among different studies. In some studies (Doña et al., 2012; Celik et al., 2014), $31.9-37 \%$ of the episodes were attributed to NSAIDs and 20.4-28.1\% to BL antibiotics (Doña et al., 2012; Çelik et al., 2014; Gabrielli et al., 2018), and the most frequent drug allergy was to multiple NSAIDs $47.29 \%$, followed by immediate reactions to BLs $18.12 \%$ (Doña et al., 2012), and these findings are similar to ours. However, another study (Gabrielli et al., 2018) reported $20.3 \%$ of patients were confirmed to NSAIDs, which was lower than our study, and $57.8 \%$ of the reactions were due to antibiotics, which was higher than ours.

In the study by Doña et al. (Doña et al., 2012), the diagnosis was established by clinical history in 742 patients (44\%), by SPTs in 246 patients (14.6\%), by in vitro testing in 176 patients $(10.4 \%)$, and by DPT in 519 patients $(30.8 \%)$. This was different from our results. We had about $79.58 \%$ patients diagnosed by clinical history alone, $12.08 \%$ by SPT, and 8.33 by DPT. These differences are explained by the escalating preferences of patients for more conservative approaches including alternative treatments, rather than performing DPT with the culprit drug.

STs or serum-specific IgE antibodies were used as methods of diagnosis in BL reactions in $70-82 \%$ of patients and DPT in 18-30\% (Bousquet et al., 2008; Kalyoncu et al., 2016), and this was in concordance with our findings, where the method to confirm diagnosis in BLs was STs in $31 \%$ of patients and a DPT in $13.7 \%$. The observed difference was likely due to not performing STs in patients with anaphylactic reactions to BLs, and instead performing drug testing with suitable alternatives (Al-Ahmad et al., 2014; Al-Ahmad and Rodriguez-Bouza, 2018). Of the five confirmed patients for opioids reactions, the diagnosis was elucidated from a positive history only (100\% of patients), compared to other studies, where they used DPT as the main diagnostic method. These differences are due to a more 
conservative approach where a suitable alternative could be found (Li et al., 2017; Powell et al., 2019).

We are aware of some limitations in our study. The most important limitation of the study is the mixing of unconfirmed and nonallergic patients in the same category. Our group was forced to do so because we were using real-life data from a registry, and even if the outcome of the test is very likely to be negative, patients who rejected or had contraindication for DPT cannot be called nonallergic, and patients with negative DPT are simply "nonallergic" and cannot be called not confirmed. The use of clinical history alone as a positive criterion should not be used if we rely on other diagnostic testing. Another limitations of the study included that some patients were unsure on which drug caused the reaction, the temporal correlation after drug exposure due to recall bias, the relatively small study population, especially for less common drug reactions, and that atopy was not routinely assessed in all patients, and therefore, atopy could not be studied as a risk factor. However, this is a prospective data-based registry, and ongoing data collection might address some of these issues in the near future.

\section{REFERENCES}

Aberer, W., Bircher, A., Romano, A., Blanca, M., Campi, P., Fernandez, J., et al. (2003). Drug provocation testing in the diagnosis of drug hypersensitivity reactions: general considerations. Allergy 58, 854-863. doi:10.1034/j.1398-9995. 2003.00279.x

Al-Ahmad, M., and Bouza, T. R. (2017). Successful desensitization to radiocontrast media in two high-risk cardiac patients. Ann. Saudi Med. 37, 333-335. doi:10. 5144/0256-4947.2017.333

Al-Ahmad, M., and Rodriguez-Bouza, T. (2018). Drug allergy evaluation for betalactam hypersensitivity: cross-reactivity with cephalosporines, carbapenems and negative predictive value. Asian Pac. J. Allergy Immunol. 36, 27-31. doi:10.12932/AP0853

Al-Ahmad, M., Rodriguez Bouza, T., and Arifhodzic, N. (2014). Penicillin allergy evaluation: experience from a drug allergy clinic in an Arabian Gulf Country, Kuwait. Asia Pac Allergy 4, 106-112. doi:10.5415/apallergy.2014.4.2.106

Ben-Shoshan, A. M., Wang, Y., Schrijvers, R., Bousquet, P. J., Mura, T., Molinari, N., et al. (2018). Designing predictive models for beta-lactam allergy using the drug allergy and hypersensitivity database. J. Allergy Clin. Immunol. Pract. 6, 139-148.e2. doi:10.1016/j.jaip.2017.04.045

Blanca, M., Torres, M. J., García, J. J., Romano, A., Mayorga, C., de Ramon, E., et al. (1999). Natural evolution of skin test sensitivity in patients allergic to betalactam antibiotics. J. Allergy Clin. Immunol. 103, 918-924. doi:10.1016/s00916749(99)70439-2

Blanca, Q., Zhang, S., Ferrando, L., Bourrain, J. L., Demoly, P., and Chiriac, A. M. (2020). Multiple drug hypersensitivity syndrome in a large database. J. Allergy Clin. Immunol. Pract. 8, 258-266.e1. doi:10.1016/j.jaip.2019.06.009

Böhm, R., and Cascorbi, I. (2016). Pharmacogenetics and predictive testing of drug hypersensitivity reactions. Front. Pharmacol. 7, 396. doi:10.3389/fphar.2016. 00396

Bourke, J., Pavlos, R., James, I., and Phillips, E. (2015). Improving the effectiveness of penicillin allergy de-labeling. J. Allergy Clin. Immunol. Pract. 3, 365-34.e1. doi:10.1016/j.jaip.2014.11.002

Bousquet, P. J., Demoly, P., Romano, A., Aberer, W., Bircher, A., Blanca, M., et al. (2009). Pharmacovigilance of drug allergy and hypersensitivity using the ENDA-DAHD database and the GALEN platform. The Galenda project. Allergy 64, 194-203. doi:10.1111/j.1398-9995.2008.01944.x

Bousquet, P. J., Pipet, A., Bousquet-Rouanet, L., and Demoly, P. (2008). Oral challenges are needed in the diagnosis of beta-lactam hypersensitivity. Clin. Exp. Allergy 38, 185-190. doi:10.1111/j.1365-2222.2007.02867.x

\section{DATA AVAILABILITY STATEMENT}

The raw data supporting the conclusions of this article will be made available by the authors, without undue reservation.

\section{ETHICS STATEMENT}

The studies involving human participants were reviewed and approved by Kuwait Research Ethics Committee at the Ministry of Health (Research study number 808/2018). Written informed consent from the participants' legal guardian/next of kin was not required to participate in this study in accordance with the national legislation and the institutional requirements.

\section{AUTHOR CONTRIBUTIONS}

All authors listed have made a substantial, direct, and intellectual contribution to the work and approved it for publication.

Brockow, K., Romano, A., Blanca, M., Ring, J., Pichler, W., and Demoly, P. (2002). General considerations for skin test procedures in the diagnosis of drug hypersensitivity. Allergy 57, 45-51. doi:10.1034/j.1398-9995.2002.13027.x

Caimmi, S., Caimmi, D., Bousquet, P. J., and Demoly, P. (2012). How can we better classify NSAID hypersensitivity reactions?--validation from a large database. Int. Arch. Allergy Immunol. 159, 306-312. doi:10.1159/000337660

Çelik, G. E., Karakaya, G., Öztürk, A. B., Gelincik, A., Abadoğlu, O., Sin, A., et al. (2014). Drug allergy in tertiary care in Turkey: results of a national survey. The ADAPT study: adult drug allergy perception in Turkey. Allergol. Immunopathol. 42, 573-579. doi:10.1016/j.aller.2013.07.007

Chiriac, A. M., Wang, Y., Schrijvers, R., Bousquet, P. J., Mura, T., Molinari, N., et al. (2018). Designing predictive models for beta-lactam allergy using the drug allergy and hypersensitivity database. J Allergy Clin. Immunol. Pract. 6, 139-148.e2. doi:10.1016/j.jaip.2017.04.045

Co Minh, H. B., Bousquet, P. J., Fontaine, C., Kvedariene, V., and Demoly, P. (2006). Systemic reactions during skin tests with beta-lactams: a risk factor analysis. J. Allergy Clin. Immunol. 117, 466-468. doi:10.1016/j.jaci.2005.10.020

Cornejo-García, F., Atanaskovic-Markovic, M., Blanca-Lopez, N., Gomes, E., Gaeta, F., Sarti, L., et al. (2019). A multicenter retrospective study on hypersensitivity reactions to nonsteroidal anti-inflammatory drugs (NSAIDs) in children: a report from the European Network on drug allergy (ENDA) group. J. Allergy Clin. Immunol. Pract. 8, 1022-1031.e1. doi:10.1016/j. jaip.2019.10.049

Decker, J. R., Brockow, K., Romano, A., Aberer, W., Torres, M. J., Bircher, A., et al. (2010). General considerations on rapid desensitization for drug hypersensitivity - a consensus statement. Allergy 65, 1357-1366. doi:10. $1111 /$ j.1398-9995.2010.02441.x

Demoly, P., and Bousquet, J. (2002). Drug allergy diagnosis work up. Allergy 57 (Suppl. 72), 37-40. doi:10.1034/j.1398-9995.57.s72.7.x

Demoly, A., Mondino, C., Viola, M., and Montuschi, P. (2003). Immediate allergic reactions to beta-lactams: diagnosis and therapy. Int. J. Immunopathol. Pharmacol. 16, 19-23. doi:10.1177/039463200301600103

Demoly, M., Bousquet, P. J., Gomes, E., Romano, A., and Demoly, P. (2012). Results of drug hypersensitivity evaluations in a large group of children and adults. Clin. Exp. Allergy 42, 123-130. doi:10.1111/j.1365-2222.2011.03887.x

Demoly, P., Adkinson, N. F., Brockow, K., Castells, M., Chiriac, A. M., Greenberger, P. A., et al. (2014). International consensus on drug allergy. Allergy 69, 420-437. doi:10.1111/all.12350

Demoly, P., Kropf, R., Bircher, A., and Pichler, W. J. (1999). Drug hypersensitivity: questionnaire. EAACI interest group on drug hypersensitivity. Allergy 54, 999-1003. doi:10.1034/j.1398-9995.1999.00247.x 
Demoly, P., Pichler, W., Pirmohamed, M., and Romano, A. (2008). Important questions in allergy: 1-drug allergy/hypersensitivity. Allergy 63, 616-619. doi:10.1111/j.1398-9995.2008.01693.x

Doña, I., Blanca-López, N., Cornejo-García, J. A., Torres, M. J., Laguna, J. J., Fernández, J., et al. (2011). Characteristics of subjects experiencing hypersensitivity to non-steroidal anti-inflammatory drugs: patterns of response. Clin. Exp. Allergy 41, 86-95. doi:10.1111/j.1365-2222.2010.03651.x

Doña, I., Blanca-López, N., Torres, M. J., García-Campos, J., García-Núñez, I., Gómez, F., et al. (2012). Drug hypersensitivity reactions: response patterns, drug involved, and temporal variations in a large series of patients. J. Investig. Allergol. Clin. Immunol. 22, 363-371.

Doña, I., Pérez-Sánchez, N., Eguiluz-Gracia, I., Muñoz-Cano, R., Bartra, J., Torres, M. J., et al. (2020). Progress in understanding hypersensitivity reactions to nonsteroidal anti-inflammatory drugs. Allergy 75, 561-575. doi:10.1111/all. 14032

Gabrielli, S., Clarke, A. E., Eisman, H., Morris, J., Joseph, L., La Vieille, S., et al. (2018). Disparities in rate, triggers, and management in pediatric and adult cases of suspected drug-induced anaphylaxis in Canada. Immun. Inflamm. Dis. 6, 3-12. doi:10.1002/iid3.201

Gamboa, P. M. (2009). The epidemiology of drug allergy-related consultations in Spanish Allergology services: alergológica-2005. J. Investig. Allergol. Clin. Immunol. 19 (Suppl. 2), 45-50.

Kalyoncu, I., Gaspar, Â., Chambel, M., Piedade, S., and Morais-Almeida, M. (2016). Hypersensitivity to beta-lactam antibiotics: a three-year study. Eur. Ann. Allergy Clin. Immunol. 48, 212-219.

Li, P. H., Ue, K. L., Wagner, A., Rutkowski, R., and Rutkowski, K. (2017). Opioid hypersensitivity: predictors of allergy and role of drug provocation testing. J. Allergy Clin. Immunol. Pract. 5, 1601-1606. doi:10.1016/j.jaip.2017.03.035

Macy, E., and Contreras, R. (2014). Health care use and serious infection prevalence associated with penicillin "allergy" in hospitalized patients: a cohort study. J. Allergy Clin. Immunol. 133, 790-796. doi:10.1016/j.jaci.2013. 09.021

Macy, E., Schatz, M., Lin, C., and Poon, K. Y. (2009). The falling rate of positive penicillin skin tests from 1995 to 2007. Perm. J. 13, 12-18. doi:10.7812/tpp/08073

Park, B. N. D., and Demoly, P. (2012). Allergy. 4th Edn, Editors M. K. C. Stephen, T. Holgate, D. H. Broide, and F. D. Martinez, 321-330.

Pichler, P. (2010). Drug allergy: an updated practice parameter. Ann. Allergy Asthma Immunol. 105, 259-273. doi:10.1016/j.anai.2010.08.002

Pipet, A., Veyrac, G., Wessel, F., Jolliet, P., Magnan, A., Demoly, P., et al. (2011). A statement on cefazolin immediate hypersensitivity: data from a large database, and focus on the cross-reactivities. Clin. Exp. Allergy 41, 1602-1608. doi:10. $1111 /$ j.1365-2222.2011.03846.x
Powell, M. Z., Mueller, S. W., and Reynolds, P. M. (2019). Assessment of opioid cross-reactivity and provider perceptions in hospitalized patients with reported opioid allergies. Ann. Pharmacother. 53, 1117-1123. doi:10.1177/ 1060028019860521

Sidoroff, S., Galéra, C., Bousquet-Rouanet, L., Arnoux, B., Demoly, P., and Bousquet, P. J. (2010). Safety of cefuroxime as an alternative in patients with a proven hypersensitivity to penicillins: a DAHD cohort survey. Int. Arch. Allergy Immunol. 153, 53-60. doi:10.1159/000301579

Simons, F. E., Ardusso, L. R., Bilò, M. B., El-Gamal, Y. M., Ledford, D. K., Ring, J., et al. (2011). World allergy organization guidelines for the assessment and management of anaphylaxis. World Allergy Organ J. 4, 13-37. doi:10.1097/ WOX.0b013e318211496c

Sousa-Pinto, B., Cardoso-Fernandes, A., Araújo, L., Fonseca, J. A., Freitas, A., and Delgado, L. (2018). Clinical and economic burden of hospitalizations with registration of penicillin allergy. Ann. Allergy Asthma Immunol. 120, 190-194.e2. doi:10.1016/j.anai.2017.11.022

Su, T., Broekhuizen, B. D. L., Verheij, T. J. M., and Rockmann, H. (2017). The impact of penicillin allergy labels on antibiotic and health care use in primary care: a retrospective cohort study. Clin. Transl. Allergy 7, 18. doi:10.1186/ s13601-017-0154-y

Thong, B. Y., and Tan, T. C. (2011). Epidemiology and risk factors for drug allergy. Br. J. Clin. Pharmacol. 71, 684-700. doi:10.1111/j.1365-2125.2010.03774.x

Thong, H. A., Muñoz-Furlong, A., Campbell, R. L., Adkinson, N. F., Jr., Bock, S. A., Branum, A., et al. (2006). Second symposium on the definition and management of anaphylaxis: summary report-second national institute of allergy and infectious disease/food allergy and anaphylaxis network symposium. Ann. Emerg. Med. 47, 373-380. doi:10.1016/j.annemergmed. 2006.01.018

Torres, M. J., Blanca, M., Fernandez, J., Romano, A., Weck, A., Aberer, W., et al. (2003). Diagnosis of immediate allergic reactions to beta-lactam antibiotics. Allergy 58, 961-972. doi:10.1034/j.1398-9995.2003.00280.x

Conflict of Interest: The authors declare that the research was conducted in the absence of any commercial or financial relationships that could be construed as a potential conflict of interest.

Copyright (c) 2021 Al-Ahmad, Edin, Musa and Rodriguez-Bouza. This is an openaccess article distributed under the terms of the Creative Commons Attribution License (CC BY). The use, distribution or reproduction in other forums is permitted, provided the original author(s) and the copyright owner(s) are credited and that the original publication in this journal is cited, in accordance with accepted academic practice. No use, distribution or reproduction is permitted which does not comply with these terms. 